\title{
Kinetic Analysis of a Naturally Occurring Bioremediation Enzyme: Dehaloperoxidase-Hemoglobin from Amphitrite ornata
}

\author{
Huan Ma, ${ }^{\dagger, \ddagger}$ Matthew K. Thompson, ${ }^{\dagger}$ John Gaff, ${ }^{\dagger}$ and Stefan Franzen*, ${ }^{*, *}$ \\ Department of Chemistry, North Carolina State University, Raleigh, North Carolina 27695, and Department of \\ Chemistry, Zhejiang University, Hangzhou, China
}

Received: February 16, 2010; Revised Manuscript Received: August 24, 2010

\begin{abstract}
The temperature dependence of the rate constant for substrate oxidation by the dehaloperoxidase-hemoglobin (DHP) of Amphitrite ornata has been measured from 278 to $308 \mathrm{~K}$. The rate constant is observed to increase over this range by approximately a factor of 2 for each $10{ }^{\circ} \mathrm{C}$ temperature increment. An analysis of the initial rates using a phenomenological approach that expresses the peroxidase ping-pong mechanism in the form of the Michaelis-Menten equation leads to an interpretation of the effects in terms of the fundamental rate constants. The analysis of kinetic data considers a combination of diffusion rate constants for substrate and $\mathrm{H}_{2} \mathrm{O}_{2}$, elementary steps involving activation and heterolysis of the $\mathrm{O}-\mathrm{O}$ bond of $\mathrm{H}_{2} \mathrm{O}_{2}$, and two electron transfers from the substrate to the iron. To complete the analysis from the perspective of turnover of substrate into product, density function theory (DFT) calculations were used to address the fate of phenoxy radical intermediates. The analysis suggests a dominant role for diffusion in the kinetics of DHP.
\end{abstract}

\section{Introduction}

The dehaloperoxidase-hemoglobin (DHP) from Amphitrite ornata has recently been shown to have a unique peroxidase enzyme mechanism that may be characterized as nonclassical competitive inhibition. ${ }^{1}$ In the nonclassical model, the inhibitor binds remotely to the active site and causes a conformational change in the enzyme that prevents substrate binding. In DHP, the substrate binds at an external site, and the inhibitor binds in the distal pocket above the heme iron. There are multiple X-ray crystal structures of 4-halophenols binding in the internal site. ${ }^{1,2}$ The location of the external site has been characterized by spectroscopic measurements. NMR spectroscopy indicates that there is an interaction between the substrate and the distal histidine, H55. ${ }^{3}$ Resonance Raman spectroscopy confirms this interaction, using the observation that the distal histidine (H55) position appears to correlate with water in the metaquo form such that H55 in the internal position stabilizes the 6-coordinate high spin state and $\mathrm{H} 55$ in the external position gives rise to the 5-coordinate high spin state. ${ }^{1,4-6}$ Models of these structures are shown in Figure 1. There are two isoforms of DHP in A. ornata. ${ }^{7}$ All previous studies that referred to DHP implicitly referenced DHP A. We have recently cloned and expressed the B isoform of DHP, DHP B ${ }^{8,9}$ so that we now distinguish the specific experiments conducted on DHP A in this study from general features that apply to both isoforms of DHP. The two isoforms are structurally homologous but differ by five amino acids: I9L, R32K, Y34N, N81S, and S91G. Although there is slight variation in the amino acid sequence, both isoforms are capable of performing the dehalogenation function.

The external substrate binding site in DHP is related to external binding in peroxidases ${ }^{10,11}$ in that electron transfer from

* To whom correspondence should be addressed: Stefan Franzen, Department of Chemistry, North Carolina State University, Raleigh, NC

27695. E-mail: stefan_franzen@ncsu.edu. Phone: 919-515-8915.

North Carolina State University.

* Zhejiang University. the substrate to the heme edge (or alternatively to an amino acid radical) ${ }^{12}$ is the key step in substrate oxidation as shown in Figure 2. Similar considerations apply to myoglobin mutants that have peroxidase activity. ${ }^{13-16}$ Amino acid radicals, which are formed in myoglobin as well as peroxidases, may act as a conduit for electron transfer or might result in protein cross-linking. ${ }^{13,17-19}$ The oxidized phenol rapidly deprotonates to form the corresponding phenoxy radical. ${ }^{20,21}$ The standard peroxidase mechanism involves disproportionation of the radical to form the phenoxy radical cation and phenolate as shown on the left side of Figure 2. Disproportionation is self-electron transfer in this case. Attack by water could occur on either the radical (right side) or the cation (left side). If attack by water occurs on the radical (right side of Figure 2), then electron transfer occurs subsequently. While the order of electron transfer and attack by water is difficult to ascertain with certainty in a kinetic experiment, it can be addressed using density functional theory (DFT) calculations.

Kinetic analysis is needed to understand the implication of the various possible pathways for one-electron activation implicit in the external binding site. ${ }^{22}$ Substrate binding and oxidation under physiological conditions are the basic physical phenomena required for application of DHP as a bioremediation enzyme. One can regard DHP as a bioremediation enzyme since its natural function is to oxidize $2,4,6$ tribromophenol (2,4,6-TBP). ${ }^{23}$ While 2,4,6-TBP is a natural pollutant made by organisms such as Notomastus lobatus and Thelepus crispus in benthic ecosystems ${ }^{23}$ 2,4,6-trichlorophenol $(2,4,6-\mathrm{TCP})$ is a man-made pollutant that is widely dispersed. ${ }^{24}$ 2,4,6-TCP and related polysubstituted chlorinated phenols are substrates for DHP, while, as we have recently shown, 4-chlorophenols are inhibitors. Since 2,4,6-TCP is an excellent substrate, as well as a bioremediation target, the present study serves as a baseline for future comparison of a range of substrates in DHP and its mutants. ${ }^{25}$ Herein, we focus on the kinetics of the uninhibited reaction using an Arrhenius analysis of the rate constants based on kinetic 
$\mathbf{A}$

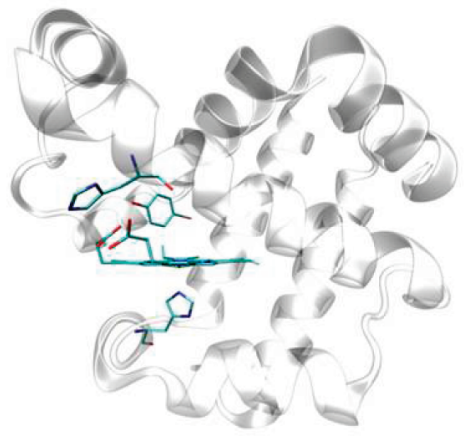

$\mathbf{C}$

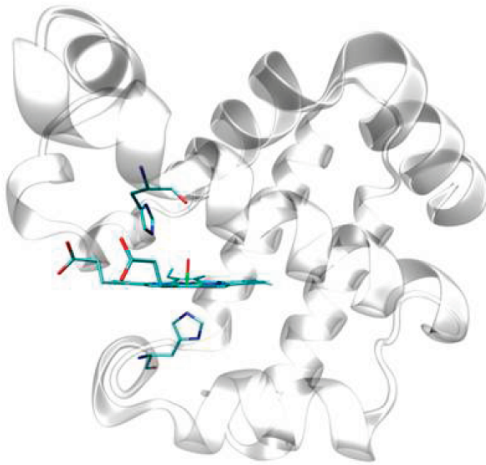

B

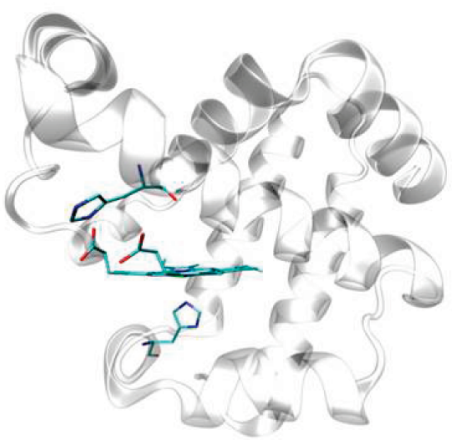

D

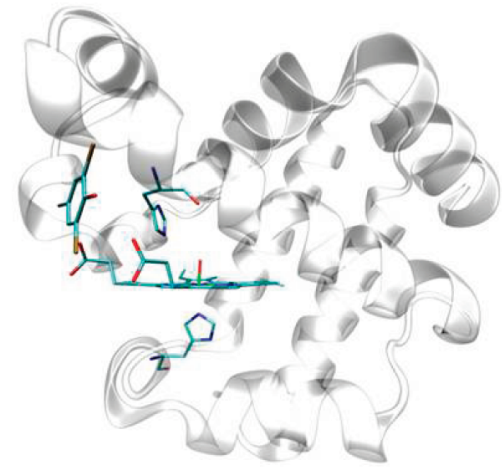

Figure 1. Structures of DHP A with substrate and inhibitor bound to the enzyme. (A) Metaquo form with inhibitor bound (3LB1 is shown, but 3LB2, 3BL3, and 3LB4 are similar in structure); H55 open. (B) Deoxy form of DHP (3DR9); H55 open. (C) Metaquo form of DHP (2QFK); H55 closed. (D) Metaquo form with the substrate at proposed external substrate binding site; H55 closed.

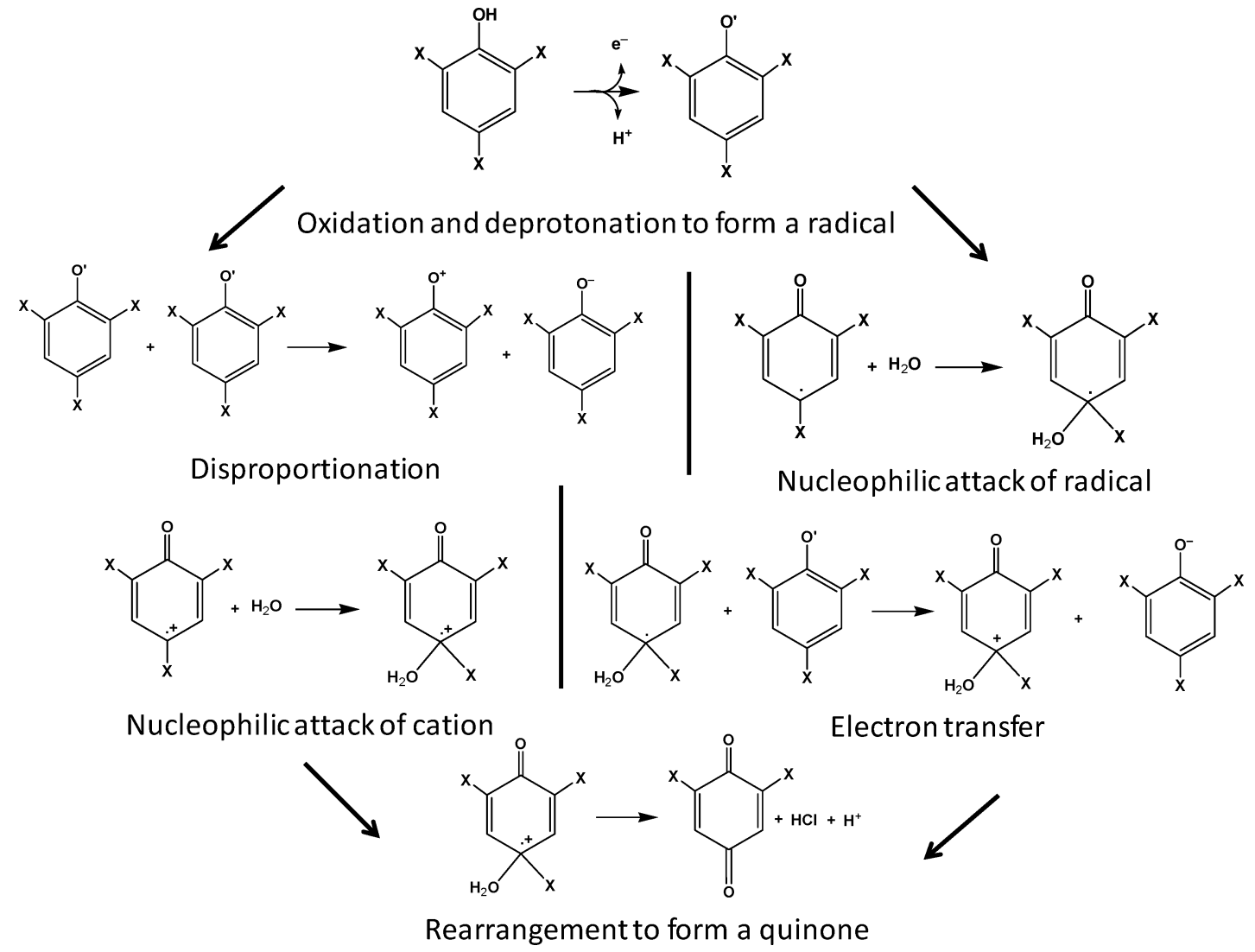

Figure 2. Possible routes from phenol to quinone subsequent electron transfer to the heme oxoferryl intermediates of the DHP A enzyme. These structures were used for DFT calculations described in the text.

models of the ping-pong mechanism. ${ }^{26}$ We show that a phenomenological model permits fit to an equation that has the form of the Michaelis-Menten equation but ultimately has an interpretation in terms of the fundamental rate constants for peroxidase kinetics. ${ }^{26}$ Finally, we consider the fate of the radical generated by the oxidation reactions of DHP. Since this process is not directly probed by the spectroscopic assay, DFT calculations are needed to deter- 
mine whether the barrier height corresponds to the measured kinetic parameters using an Arrhenius approach.

\section{Materials and Methods}

DHP A Protein Growth. A pET-16b plasmid containing the 6XHis-tagged DHP A DNA insert was transformed into competent BL21(DE3) Escherichia coli cells and then plated with $100 \mu \mathrm{g} / \mathrm{mL}$ ampicillin and allowed to grow at $37{ }^{\circ} \mathrm{C}$ for about $14 \mathrm{~h}$. Single colonies were isolated and transferred to 2 $\mathrm{mL}$ starter growths of $2 \mathrm{xYT}$ broth containing $75 \mu \mathrm{g} / \mathrm{mL}$ of ampicillin at $37{ }^{\circ} \mathrm{C}$ with shaking for about $8 \mathrm{~h}$. A portion of 1 $\mathrm{mL}$ of each starter growth was then used to inoculate six $1 \mathrm{~L}$ flasks of 2xYT broth containing $75 \mu \mathrm{g} / \mathrm{mL}$ of ampicillin. The 6 L E. coli growth was incubated at $37^{\circ} \mathrm{C}$ with shaking for about $15 \mathrm{~h}$. The cells were collected via centrifugation at $7000 \mathrm{rpm}$, at $4{ }^{\circ} \mathrm{C}$ for $20 \mathrm{~min}$.

Purification of 6XHisDHP A. The E. coli cell pellet was resuspended in $2 \mathrm{~mL} /$ (gram cell pellet) of lysis buffer $(50 \mathrm{mM}$ $\mathrm{NaH}_{2} \mathrm{PO}_{4}, 300 \mathrm{mM} \mathrm{NaCl}, 10 \mathrm{mM}$ imidazole, $\mathrm{pH}$ 8), and lysozyme was added to a final concentration of $1 \mathrm{mg} / \mathrm{mL}$. The cell slurry was stirred at $4{ }^{\circ} \mathrm{C}$ for an hour and then sonicated for $30 \mathrm{~min}$, and $500 \mu \mathrm{L}$ of DNase I $(10 \mathrm{mg} / \mathrm{mL})$ and RNase A $(16 \mathrm{mg} / \mathrm{mL})$ were added. The cell slurry was then stirred again at $4{ }^{\circ} \mathrm{C}$ for $1 \mathrm{~h}$ before freezing overnight at $-20{ }^{\circ} \mathrm{C}$. After rethawing, the cells were centrifuged at $18000 \mathrm{rpm}$ for half an hour, and the supernatant containing the 6XHisDHP A was collected. The crude DHP A solution was applied to a Ni-NTA agarose column (5 Prime Perfect Pro), washed with washing buffer $\left(50 \mathrm{mM} \mathrm{NaH}{ }_{2} \mathrm{PO}_{4} 300 \mathrm{mM} \mathrm{NaCl}, 20 \mathrm{mM}\right.$ imidazole, $\mathrm{pH}$ 8), and eluted using elution buffer $\left(50 \mathrm{mM} \mathrm{NaH}_{2} \mathrm{PO}_{4}, 300\right.$ $\mathrm{mM} \mathrm{NaCl}, 250 \mathrm{mM}$ imidazole, $\mathrm{pH}$ 8). The isolated 6XHis DHP A from the column was oxidized by excess $10 \mathrm{mM} \mathrm{K}_{3}\left[\mathrm{Fe}(\mathrm{CN})_{6}\right]$. Excess $\mathrm{K}_{3}\left[\mathrm{Fe}(\mathrm{CN})_{6}\right]$ was removed by gel filtration on a Sephadex G-25 column, which permitted simultaneous buffer exchange into $20 \mathrm{mM} \mathrm{KH} \mathrm{PO}_{4} \mathrm{pH} 6$ buffer. The oxidized protein was loaded onto a $\mathrm{CM}-52$ column for further purification. Once loaded onto the column, the 6XHis DHP A was washed with $20 \mathrm{mM} \mathrm{KH}_{2} \mathrm{PO}_{4} \mathrm{pH} 6$ and eluted form the column with $150 \mathrm{mM} \mathrm{KH}_{2} \mathrm{PO}_{4} \mathrm{pH} 7$ buffer. The concentration of the ferric DHP A was determined using the Soret absorption intensity at $406 \mathrm{~nm}$ with a molar absorptivity of $116400 \mathrm{M}^{-1}$ $\mathrm{cm}^{-1}$. The purified 6XHisDHP A was stored at $4{ }^{\circ} \mathrm{C}$ for future use.

Sample Preparation. Purified 6XHisDHP A was oxidized in the presence of $10 \mathrm{mM} \mathrm{K}_{3}\left[\mathrm{Fe}(\mathrm{CN})_{6}\right]$, separated from excess $\mathrm{K}_{3}\left[\mathrm{Fe}(\mathrm{CN})_{6}\right]$ by gel filtration on Sephadex G-25, and further purified on CM-52 (as above) prior to each experiment. For kinetic assays the elution buffer was $150 \mathrm{mM} \mathrm{KH}_{2} \mathrm{PO}_{4}$ buffer at $\mathrm{pH}$ 7.0. A portion of $98 \%$ 2,4,6-tricholorophenol from Acros Organics (Lot No. A0245137) was dissolved in $150 \mathrm{mM}$ $\mathrm{KH}_{2} \mathrm{PO}_{4}, \mathrm{pH} 7$ buffer with a final concentration of $3 \mathrm{mM}$ and stored at $4{ }^{\circ} \mathrm{C}$ until use. The $\mathrm{H}_{2} \mathrm{O}_{2}$ solution was prepared from $30 \%$ reagent grade $\mathrm{H}_{2} \mathrm{O}_{2}$ solution from Fisher Chemicals in 150 $\mathrm{mM} \mathrm{KH} \mathrm{KO}_{4}$, $\mathrm{pH} 7$ buffer to a final concentration of $17.6 \mathrm{mM}$ for the stock solution. The $\mathrm{H}_{2} \mathrm{O}_{2}$ solution was prepared freshly before use and stored at $4{ }^{\circ} \mathrm{C}$ during the course of a series of experiments.

Kinetic Assays. The kinetic assays were conducted in a 0.4 $\mathrm{cm}$ path length quartz cuvette with a total volume of $1500 \mu \mathrm{L}$. The final concentration of ferric DHP A in the cuvette was $[\mathrm{E}]_{\mathrm{T}}$ $\sim 2.4 \mu \mathrm{M}$, and substrate, 2,4,6-TCP, concentrations were varied from 100 to $1900 \mu \mathrm{M}$. Spectra were obtained using a photodiode UV-vis spectrometer (Agilent 8453) equipped with a Peltier temperature controller using benchtop mixing of the reagents.
To reach thermal equilibrium, DHP A and 2,4,6-TCP (150 mM $\mathrm{KH}_{2} \mathrm{PO}_{4}, \mathrm{pH}=7$ buffer) were allowed to incubate for $5 \mathrm{~min}$ in the cuvette placed in the thermal cell. The $\mathrm{H}_{2} \mathrm{O}_{2}$ solution, with a final concentration of 500 times DHP A, was injected into the cuvette within one second of initiation of data collection. The data were measured over the wavelength range from 200 to $700 \mathrm{~nm}$ with a time resolution of $3.1 \mathrm{~s}$. The wavelength monitored during kinetic measurements was $273 \mathrm{~nm}$, the peak of the product absorption band. For 2,6-DCQ, $\varepsilon_{273}$ is 14130 $\mathrm{M}^{-1} \mathrm{~cm}^{-1}$ at $\mathrm{pH}$ 7. Data were extracted using an Excel spreadsheet and analyzed using Igor Pro 5.0.

Kinetic Analysis. The purpose of this kinetic assay is to study the relationship between enzymatic reaction initial velocity and temperature. The obtained data were first fit to a linear function to get the initial reaction velocity at a given substrate concentration. Then those initial velocities of different substrate concentrations were fit to the Michaelis-Menten equation to obtain relevant parameters $k_{\mathrm{cat}}$ and $K_{\mathrm{M}}$. Finally, the relationship between these parameters and temperature was analyzed using a phenomenological Arrhenius equation. The enzyme-substrate (ES) complex is formed reversibly in the Michaelis-Menten mechanism. However, in peroxidase chemistry there are two complexes, one with the substrate, 2,4,6-TCP, and one with $\mathrm{H}_{2} \mathrm{O}_{2}$. According to the standard enzyme kinetic scheme, the binding of $\mathrm{H}_{2} \mathrm{O}_{2}$ leads to formation of compound $\mathrm{I}$ and is not reversible. We have recently shown that compound $\mathrm{I}$ is not observed in DHP A and that compound ES is rapidly formed. ${ }^{12}$ We recently confirmed similar observations for DHP B. ${ }^{9}$ Both compound I and compound $\mathrm{ES}$ consist of a $\mathrm{Fe}(\mathrm{IV})=\mathrm{O}$ species and a cation radical. The difference is that the radical resides on the heme ring in compound I but on an aromatic amino acid in comound ES. We have further shown that the radical is located on one of the five tyrosines in DHP A. ${ }^{12}$ Since compound ES formation appears to be rapid in DHP, we present the peroxidase rate scheme with a compound ES intermediate. The compound ES is reduced in two one-electron steps by a substrate, $\mathrm{XAOH}$, which is 2,4,6-TCP in the present study. The sequential oxidation of two substrates by two different processes with rate constants $k_{2}$ and $k_{3}$ is known as the ping-pong mechanism.

The kinetic model for this rate scheme is given by:

$$
\begin{gathered}
V_{\mathrm{o}}=\frac{V_{\max }[\mathrm{XAOH}]}{K_{\mathrm{m}}+[\mathrm{XAOH}]} \\
V_{\max }=k_{1}\left[\mathrm{H}_{2} \mathrm{O}_{2}\right][\mathrm{E}]_{\mathrm{o}} \quad K_{\mathrm{m}}=\left(\frac{1}{k_{2}}+\frac{1}{k_{3}}\right) k_{1}\left[\mathrm{H}_{2} \mathrm{O}_{2}\right]
\end{gathered}
$$

Dunford does not recommend the use of the Michaelis-Menten model since $k_{1} \gg k_{2}$ for well-studied peroxidases such as HRP. ${ }^{26}$ Consequently, compound I (Cmp I) is rapidly formed and can build up to an appreciable concentration in these peroxidases for a period of minutes or even longer in very pure preparations. According to eq 1, the dependence of $V_{\mathrm{o}}$ on $[\mathrm{XAOH}]$ is linear for $k_{1} \gg k_{2}$, and saturation should not be observed. ${ }^{26}$ However, DHP A does not behave like HRP in this regard. ${ }^{27,28}$ If we consider that compound ES plays the role of compound I in DHP A, ${ }^{12}$ then $k_{1}$ and $k_{2}$ are not vastly different in magnitude in DHP A. Accordingly, the results presented in this study show that saturation is observed in DHP A. These observations justify the parametrization in eq 1 . The product is formed by disproportionation of the radical intermediate $\mathrm{A} \cdot$. The $\mathrm{H}_{2} \mathrm{O}_{2}$ concen- 


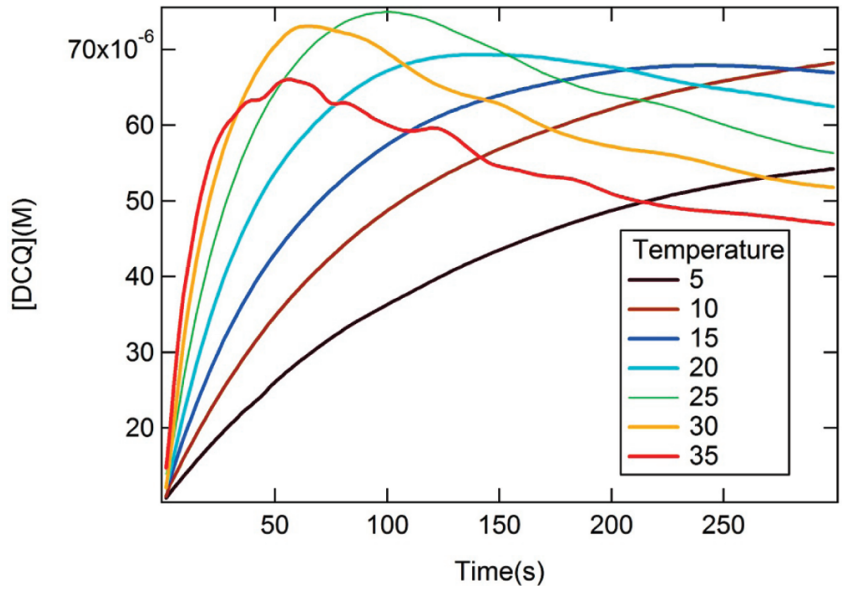

Figure 3. Single wavelength kinetics at $273 \mathrm{~nm}$ of the oxidation reaction of TCP by DHP as a function of time and product DCQ concentration obtained using a UV-vis spectrometer. Assay conditions were [ferric DHP] $\sim 2 \mu \mathrm{M},[\mathrm{TCP}] \sim 150 \mu \mathrm{M},\left[\mathrm{H}_{2} \mathrm{O}_{2}\right] \sim 150 \mu \mathrm{M}$, pH 7 KP buffer.

tration was held constant at $1.2 \mathrm{mM}$ in this study so that only the substrate concentration, $[\mathrm{XAOH}]$, is considered here.

DFT Calculations. Substrates involved in the two pathways, Figure 2, were constructed using the software package Materials Studio (Accelrys). All quantum chemical calculations were performed in a water environment with the electronic structure package DMol. ${ }^{3,30-33}$ Ground state geometries of the substrates (without the protein) were optimized using the conjugate gradient method constrained to an energy difference of $<10^{-6}$ $\mathrm{Ha}$, the Perdew-Burke-Ernzerhof $(\mathrm{PBE})^{29}$ density functional, and with a double numeric basis set with one polarization function. To achieve self-consistent field energy convergence for each optimization cycle the thermal treatment of electron occupancy ${ }^{34}$ with an electronic temperature of 0.02 Hartrees was implemented. To incorporate solvent effects, the COSMO (dielectric screening model) module employed by $\mathrm{DMol}^{3}$ was also implemented. For the solvent used in this study, water, the dielectric constant adopted was $\varepsilon=80.4 .{ }^{35}$

\section{Results}

Kinetic data were obtained as both time-dependent spectra and single-wavelength kinetics. The single wavelength kinetics were analyzed first to determine the appropriate temperature range for spectral measurement.

The single wavelength $(273 \mathrm{~nm})$ kinetics shown in Figure 3 give the change in the concentration of the product 2,6dichlorophenol-1,4-benzoquinone (2,6-DCQ) at seven different temperatures. The change in the product concentration is assumed to be proportional to the enzymatic rate. However, the concentration of 2,6-DCQ reaches a maximum and begins to decrease at longer times when the temperature is greater than $20{ }^{\circ} \mathrm{C}$. The decrease in absorbance on time scales of $50 \mathrm{~s}$ and longer is due to secondary hydrolysis reactions of the 2,6-DCQ product. ${ }^{36}$ Because of the secondary reaction, only the short time kinetics were used to estimate the catalytic rate for the process. This choice is consistent with the common practice of confining analysis of Michaelis-Menten kinetics to the initial rates.

The initial rates of appearance of the product 2,6-DCQ at $273 \mathrm{~nm}$ at five different temperatures are shown in Figure 4 as a function of substrate, 2,4,6-TCP, concentration. As expected, on the basis of the kinetics in Figure 3, Figure 4 shows that the initial rate of the enzyme reaction between DHP A and 2,4,6$\mathrm{TCP}$ at $\mathrm{pH} 7$ has a strong temperature dependence. The initial

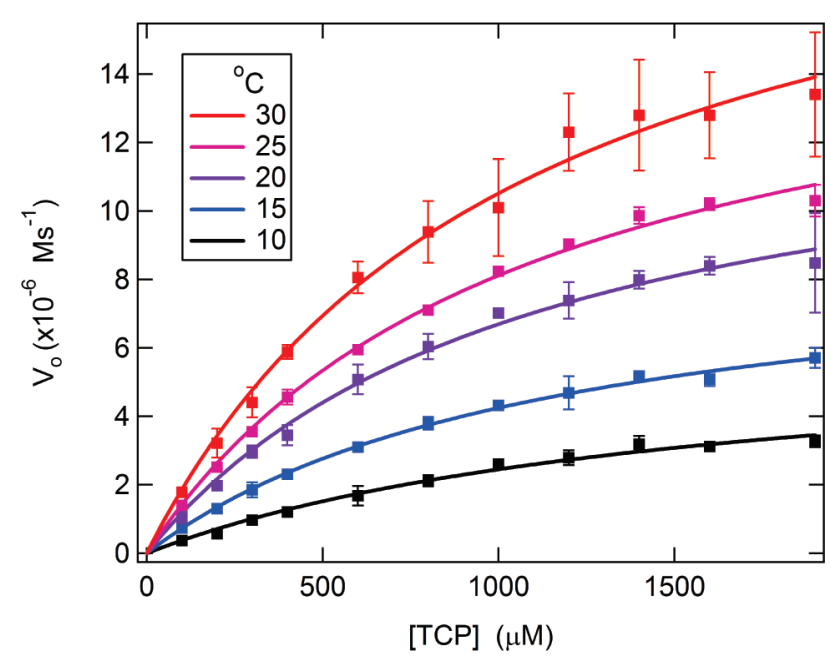

Figure 4. Single wavelength kinetics of oxidation of TCP by DHP as a function of substrate TCP concentration and enzymatic reaction initial velocity. The assay conditions were ferric DHP $\sim 2 \mu \mathrm{M}, 150 \mu \mathrm{M}$ TCP $\mathrm{M}, \mathrm{H}_{2} \mathrm{O}_{2}, 150 \mu \mathrm{M}$ pH $7 \mathrm{~KB}$ buffer.

TABLE 1: Kinetic Parameters from the Curve Fitting to the Phenomenological Michaelis-Menten Equation

\begin{tabular}{cccc}
\hline$T / \mathrm{K}$ & $V_{\max } / \mu \mathrm{M} \mathrm{s}^{-1}$ & $k_{\text {cat }} / \mathrm{s}^{-1}$ & $K_{\mathrm{M}} / \mathrm{mM}$ \\
\hline 283 & 6.32 & 2.68 & 1.58 \\
288 & 9.16 & 3.88 & 1.16 \\
293 & 14.2 & 6.00 & 1.13 \\
298 & 16.9 & 7.16 & 1.08 \\
303 & 21.7 & 9.19 & 1.06
\end{tabular}

rate data were fit to eq 1 , and from the curve fitting, we can determine the phenomenological Michaelis constant and the catalytic constant, $K_{\mathrm{M}}$ and $k_{\text {cat }}$, respectively. Table 1 provides a summary of the Michaelis-Menten fit parameters for the initial rate data.

Using the phenomenological Michaelis-Menten equation, the turnover number is $k_{\text {cat }}=V_{\max } /[\mathrm{E}]_{T}=k_{1}\left[\mathrm{H}_{2} \mathrm{O}_{2}\right]$. According to the parametrization presented in eq 1 , the phenomenological $k_{\text {cat }}$ is a pseudofirst order rate constant (i.e., $\left[\mathrm{H}_{2} \mathrm{O}_{2}\right]$ is constant) that represents the activation of the heme iron to form compound ES. Figure 5 presents an analysis of $k_{\text {cat }}$ as a function of temperature based on the Arrhenius equation, $k=A \mathrm{e}^{-E_{\mathrm{a}} / R T}$. The fit shown in Figure 5 is from the linearized form $\ln k=-E_{\mathrm{a}} l$ $R T+\ln A$. Here the parameter $A$ is defined as the preexponential or Arrhenius factor. $E_{\mathrm{a}}$ is called the activation energy, and $R$ is the universal gas constant. Figure 5 shows that the plot of $\ln k$ against $1 / T$ is reasonably approximated by a straight line with slope equal to $-E_{\mathrm{a}} / R$ and intercept equal to $\ln A$. The slope of the line found from the fit corresponds to an activation energy of $E_{\mathrm{a}}=44 \mathrm{~kJ} / \mathrm{mol}$.

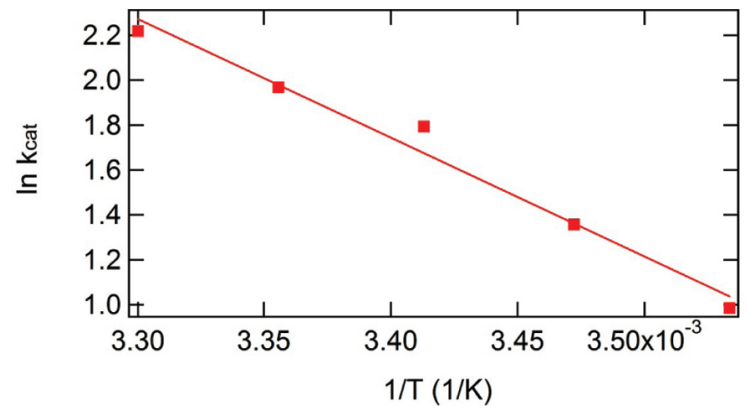

Figure 5. Plot of $\ln \left(k_{\text {cat }}\right)$ vs $1 / T$ with a fit to a line according to the Arrhenius equation $\ln k_{\mathrm{cat}}=-E_{\mathrm{a}} / R T+\ln A$. $k_{\mathrm{cat}}$ was obtained from the fit of the initial velocity data to eq 1 . 


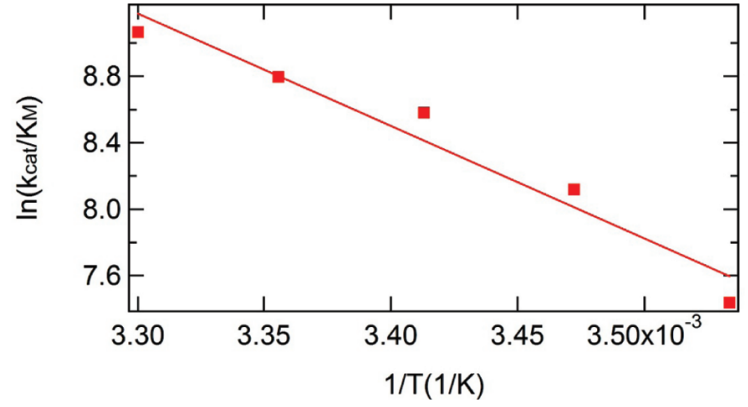

Figure 6. Linear fit of $\ln \left(k_{\text {cat }} / K_{\mathrm{M}}\right)$ vs $1 / T$ according to Arrhenius equation (Table 1 ). $k_{\text {cat }} / K_{\mathrm{M}}$ is sometimes called the efficiency of the enzyme.

TABLE 2: Calculated Gibbs Free Energies

\begin{tabular}{|c|c|}
\hline compound & $G_{\mathrm{r}, \mathrm{M}}(\mathrm{kJ} / \mathrm{mol})$ \\
\hline \multicolumn{2}{|c|}{ Disproportionation } \\
\hline TCPR & -93.696 \\
\hline $\mathrm{TCP}^{+}$ & -94.036 \\
\hline $\mathrm{TCP}^{-}$ & -94.156 \\
\hline \multicolumn{2}{|c|}{ Nucleophilic Attack of Radical } \\
\hline TCPR & -93.642 \\
\hline $\mathrm{TCPR}+\mathrm{H}_{2} \mathrm{O}$ & -106.80 \\
\hline \multicolumn{2}{|c|}{ Nucleophilic Attack of Cation } \\
\hline TCPRC & -93.889 \\
\hline $\mathrm{TCPRC}+\mathrm{H}_{2} \mathrm{O}$ & -104.64 \\
\hline \multicolumn{2}{|c|}{ Formation of Quinone } \\
\hline DCQ & -91.377 \\
\hline $\mathrm{HCl}$ & -47.081 \\
\hline $\mathrm{H}_{2} \mathrm{O}$ & -48.173 \\
\hline
\end{tabular}

Figure 6 shows a plot of the logarithm of $\ln \left(k_{\mathrm{cat}} / K_{\mathrm{M}}\right)$ as a function of $1 / T$. Although $k_{\text {cat }} / K_{\mathrm{M}}$ in the Michaelis-Menten scheme is a second-order rate constant related to enzymatic efficiency when substrate concentration is high, the phenomenological expression according to eq 1 is proportional to $k_{2} k_{3} /$ $\left(k_{2}+k_{3}\right)$, which represents the combined rate constant for substrate oxidation. Figure 6 shows that the activation energy for this process is $E_{\mathrm{a}}=56.3 \mathrm{~kJ} / \mathrm{mol}$.

Using DFT calculations, the change in Gibbs free energy for each step of the two pathways shown in Figure 2 were calculated. Table 2 provides the calculated Gibbs free energy for each of the reaction participants in the proposed mechanism. According to the reactions, the first mechanism after the formation of a radical involves disproportionation $(-0.8 \mathrm{~kJ} /$ $\mathrm{mol})$ followed by nucleophilic attack of a cation by water $(+37.4$ $\mathrm{kJ} / \mathrm{mol}$ ). The second mechanism involves nucleophilic attack of a radical by water $(+35.0 \mathrm{~kJ} / \mathrm{mol})$ followed by electron transfer $(+1.7 \mathrm{~kJ} / \mathrm{mol})$. Thus, the net combined barrier height is calculated to be +36.6 and $+36.7 \mathrm{~kJ} / \mathrm{mol}$ for the left and right side pathways shown in Figure 2, respectively. The final step involving rearrangement to form the product 2,6-DCQ is exergonic with $\Delta_{\text {quinone }} G^{\mathrm{o}}=-33.8 \mathrm{~kJ} / \mathrm{mol}$.

\section{Discussion}

The analysis of the temperature dependence of the rate constants in the peroxidase scheme provides activation energies and mechanistic information on the steps leading to catalysis in DHP A. We have used 2,4,6-TCP as a substrate because it is more soluble than the native substrate, 2,4,6-TBP. First we consider secondary reactions that occur subsequent to the rate constants analyzed here. Second, we will discuss the interpretation of the activation energies of the rate constants, $k_{1}, k_{2}$, and

\section{SCHEME 1: Rate Scheme for Peroxidase Catalysis}

$$
\begin{gathered}
\mathrm{DHP}+\mathrm{H}_{2} \mathrm{O}_{2} \stackrel{k_{1}}{\rightarrow} \mathrm{Cmp} E S+\mathrm{H}_{2} \mathrm{O} \\
\mathrm{CmpES}+\mathrm{XAOH} \stackrel{k_{2}}{\rightarrow} \mathrm{CmpII}+A \\
\stackrel{k_{3}}{\rightarrow} \mathrm{DHP}+A .
\end{gathered}
$$

$k_{3}$ in the peroxidase kinetic scheme. Next, we will discuss 2,6DCQ product formation via a radical pathway, which appears to be rapid compared to any subsequent secondary reactions, and finally we present DFT calculations to address the mechanism of the disproportion of radicals to give the product.

We have identified a second reaction on longer time scales, which depletes the product 2,6-DCQ. This reaction is highly activated and has a negligible rate below $20{ }^{\circ} \mathrm{C}$. It is approximately one order of magnitude slower than product formation even at the highest temperature. It has been shown elsewhere, and we have independently confirmed, that the second process is the reaction of 2,6-DCQ with $\mathrm{H}_{2} \mathrm{O}_{2}$ to produce 3-hydroxy-2,6,-DCQ, which proceeds even uncatalyzed in solution. ${ }^{36}$ Although the further reactions of 2,6-DCQ do not interfere with the analysis presented here, they are of interest as steps on the path to the total dechlorination of 2,4,6-TCP and will be considered elsewhere. Figure 3 shows that these processes are significant only at $T>20^{\circ} \mathrm{C}$. However, since the initial rate constant for 2,4,6-TCP oxidation also increases over this same temperature range, the separation of time scales between the first and the subsequent steps is maintained such that the initial rate approximation still holds for the determination of the enzyme kinetic parameters. The formation of a less active form of DHP A, known as compound RH, is a second process that occurs on a slower time scale. ${ }^{12}$ The inactivation of catalyst has also been considered in a kinetic model for oxidation of 2,4,6-TCP by Fe(III) meso-tetra(4-sulfonatophenyl)porphine that has strong parallels with DHP A catalysis. ${ }^{36}$ Specifically, there is a slow process (conversion to $\mathrm{RH}$ ) that alters catalytic efficiency of the catalyst without necessarily completely abolishing that activity.

The phenomenological analysis in terms of a Michaelis-Menten kinetic scheme provides insight into the two fundamental processes required for catalysis by DHP. The catalytic rate constant, $k_{\text {cat }}$, is apparently proportional to $k_{1}$, the rate constant for formation of compound ES, the first active species. The efficiency, $k_{\text {cat }} / K_{\mathrm{M}}$, is proportional to the overall substrate oxidation rate constant $k_{2} k_{3} /\left(k_{2}+k_{3}\right)$. The oxidized substrate rapidly loses $\mathrm{H}^{+}$to become a 2,4,6-trichlorophenoxy radical (2,4,6-TCPR). The radical can react by disproportionation to form 2,4,6-TCP and 2,4,6-trichlorophenoxy radical cation $(2,4,6-$ TCPRC). Here we do not consider the possibility that a second electron transfer to the heme iron by 2,4,6-TCPR immediately leads to product but rather follows the well-established precedent in the peroxidase literature shown in Scheme 1 that the mechanism consists of two one-electron processes similar to the peroxidase family of enzymes. ${ }^{37}$ Previous consideration of a two-electron model for DHP was an attempt to rationalize the hypothesis that the substrate binding site is in the distal pocket. ${ }^{27,28}$ However, we now know that the distal pocket is an inhibitor binding site and the substrate binding site is external as is commonly observed in peroxidases. $1,3,38-40$

According to the mechanism in Scheme 1, the rate constant, $k_{1}$, is a bimolecular rate constant for the formation of compound 
ES. The temperature dependence of the pseudofirst-order rate constant, $k_{1}\left[\mathrm{H}_{2} \mathrm{O}_{2}\right]$, arises primarily from the $\mathrm{H}_{2} \mathrm{O}_{2}$ binding and activation steps required to break the $\mathrm{O}-\mathrm{O}$ bond. The distal histidine, H55, acts as an acid-base catalyst for these steps. The energy barrier of $44 \mathrm{~kJ} / \mathrm{mol}$ determined from the Arrhenius analysis applies to the bond-breaking step.

The rate constants $k_{2}$ and $k_{3}$ are bimolecular rate constants that represent the combination of the diffusion rate constant, $k_{\mathrm{d}}$, for formation of the enzyme-substrate complex and the electron transfer rate constant, $k_{\mathrm{ET}}^{\mathrm{ES}, \mathrm{II}}$, from substrate to compounds ES and II, respectively. ${ }^{41}$

$$
k_{2,3}=k_{\mathrm{d}} /\left(1+K_{\mathrm{D}} k_{\mathrm{d}} / k_{\mathrm{ET}}^{\mathrm{ES}, \mathrm{II}}\right)
$$

Here, $K_{\mathrm{D}}$ is the dissociation equilibrium constant, where $K_{\mathrm{D}}=$ $k_{-\mathrm{d}} / k_{\mathrm{d}}$. The electron transfer barrier height has a major contribution from the outer sphere reorganization energy, $\lambda$, which has been estimated to be in the range of $0.5-1.25 \mathrm{eV}$ for peroxidases. ${ }^{41,42}$ If the electron transfer driving force were $\varepsilon=$ 0 and the reorganization energy were $1.25 \mathrm{eV}$, then the barrier height would be $E=(\lambda-\varepsilon)^{2} / 4 \lambda=0.375 \mathrm{eV}$. This is a maximal value since smaller values of the energy gap, $\varepsilon$, or reorganization energy, $\lambda$, will decrease $E$. On the basis of this estimate, electron transfer can only account for part of the $0.58 \mathrm{eV}(56 \mathrm{~kJ} / \mathrm{mol})$ barrier height obtained from the kinetic analysis of the Michaelis-Menten equations, and the diffusion rate constant, $k_{\mathrm{d}}$, may be rate limiting. However, it is reasonable to assume that $k_{\mathrm{d}}$ increases with temperature. Hence, the origin of the kinetic effect is likely to arise from subsequent diffusioncontrolled steps such as disproportionation and attack by water to produce the quinone product (Figure 2).

The unusual oxidation kinetics of 2,4,6-TCP by metalloporphyrins arise from the fact that the catalyst concentration determines the amount of oxidized product but not the rate of oxidation. ${ }^{36}$ This type of behavior also suggests that the electron transfer from substrate to catalyst (i.e., heme iron or tyrosine) is not rate limiting. The catalyst concentration may be a limiting reagent due to diffusion control as well as other factors such as inactivation by conversion to a less active form. This type of process is not entirely unexpected for reactions involving strong oxidants such as $\mathrm{H}_{2} \mathrm{O}_{2}$. Nonetheless, it is consistent with ratelimiting steps elsewhere in the sequence of steps that lead to product.

Figure 2 shows two pathways that involve attack by $\mathrm{H}_{2} \mathrm{O}$, either on the radical or the radical cation, to displace chloride. DFT calculations have been employed to determine which of the reaction pathways in Figure 2 occurs by calculating the change in Gibbs free energy for each step. First, the analysis for the disproportionation reaction yields $\Delta_{\text {disprop }} G^{\mathrm{o}}=-0.8 \mathrm{~kJ} /$ mol followed by an attack on the cation radical, $\Delta_{\text {phenoxy_cat }} G^{0}$ $=+37.4$, to lead to an overall energy barrier of $+36.6 \mathrm{~kJ} / \mathrm{mol}$ shown as the blue pathway in the energy level diagram in Figure 7. The alternative pathway consists of attack on the phenoxy radical by a water with a free energy change of $\Delta_{\text {phenoxy_rad }} G^{\mathrm{o}}=$ $+35.0 \mathrm{~kJ} / \mathrm{mol}$ followed by electron transfer, $\Delta_{\text {elec_trans }} G^{\circ}=+1.7$ $\mathrm{kJ} / \mathrm{mol}$, to give an overall energy barrier of $+36.7 \mathrm{~kJ} / \mathrm{mol}$ (shown as the red pathway in Figure 7. Although the overall barrier heights are so similar that the two pathways appear equally likely, Figure 7 makes it clear that disproportionation will dominate in a thermodynamic sense. Since water is present in a much greater concentration than the substrate, required for the bimolecular disproportionation, there is still a kinetic issue to consider. Given the consideration above, the electron transfer

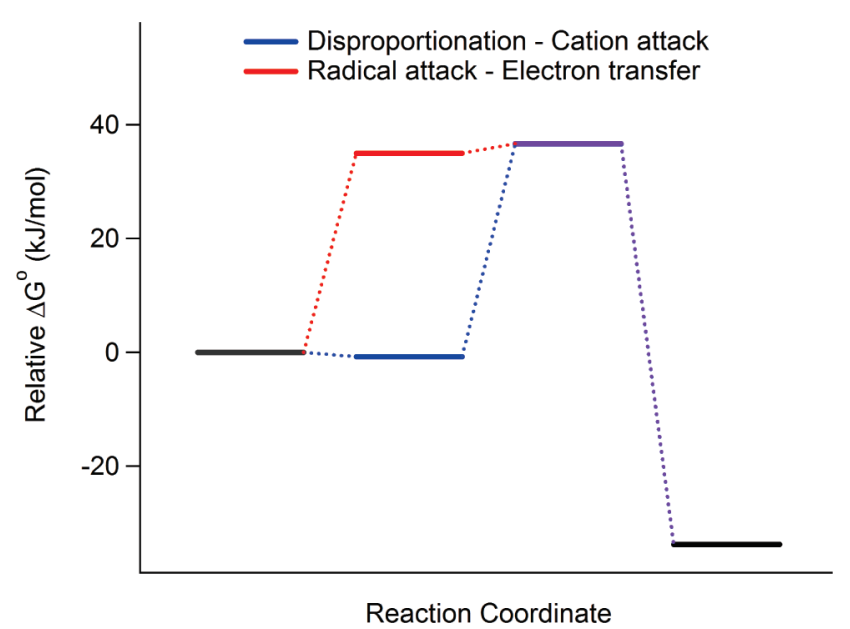

Figure 7. Energy level diagram based on DFT calculations.

from the heme (or amino acid radicals in the protein) is unlikely to account for the measured barrier heights in the Arrhenius kinetic analysis. Therefore, we suggest that the calculated barrier height of $36.6 \mathrm{~kJ} / \mathrm{mol}$ is the dominant contribution to the measured barrier height of $56 \mathrm{~kJ} / \mathrm{mol}$ for $k_{\mathrm{cat}} / K_{\mathrm{M}}$. Finally, we propose the hypothesis that the solution portion of the reaction consists of a disproportionation followed by attack of a phenoxy cation by water. Although we have given a complete analysis of the fundamental rate constants in terms of a pseudoMichaelis-Menten scheme and demonstrated saturation, our analysis suggests that the rate-limiting steps for product formation may occur apart from the enzyme itself.

\section{Conclusion}

DHP is a unique dual function enzyme. Since it functions as both a hemoglobin and a dehaloperoxidase, it has features that distinguish it from other peroxidases. Two specific unique features are the internal binding site and a switch in function that may be linked to the flexibility of H55. To understand the activation energy for the various steps in the oxidation of substrate, we have measured the temperature dependence of the oxidation of 2,4,6-TCP to 2,6-DCQ. We applied the analysis of Dunford ${ }^{26}$ and compared it to a Michaelis-Menten analysis to show that the rate constants, $k_{1}, k_{2}$, and $k_{3}$, of the ping-pong mechanism can be understood in a mechanism that gives saturation of the rate at a high substrate concentration. This type of kinetic result, which is valid for DHP, is distinct from enzymes such as HRP, which have very large $k_{1}$ and do not exhibit saturation. On the basis of the fit to an Arrhenius model, we were able to understand the temperature dependence of phenomenological $k_{\text {cat }}$ and $k_{\text {cat }} / K_{\mathrm{M}}$, which correspond to $k_{1}\left[\mathrm{H}_{2} \mathrm{O}_{2}\right]$ and $k_{2} k_{3} /\left(k_{2}+k_{3}\right)$, respectively. The activation energies are 44 and $56 \mathrm{~kJ} / \mathrm{mol}$, respectively, for these two processes. The ratelimiting process is $k_{2} k_{3} /\left(k_{2}+k_{3}\right)$, which has an activation energy that is fairly typical for chemical reactions. An anecdotal rule of thumb suggests that the rate constant for many diffusioncontrolled reactions increases by a factor of 2 for each $10^{\circ} \mathrm{C}$, which corresponds to an activation energy of $54 \mathrm{~kJ} / \mathrm{mol}$. The rate constant for substrate oxidation in DHP is close to that value, probably because of the diffusion-controlled nature of the solution reactions involving the radical $\mathrm{XAO} \cdot$ that leads to product formation.

We have analyzed the mechanism of the respective steps to understand the origins of the activation energy. The rate constant for the formation of the compound $\mathrm{ES}, k_{1}\left[\mathrm{H}_{2} \mathrm{O}_{2}\right]$, reflects the rate-limiting step in the catalytic rearrangement of $\mathrm{H}_{2} \mathrm{O}_{2}$ bound 
to the heme iron followed by electron transfer from a tyrosine. The second and third processes, $k_{2} k_{3} /\left(k_{2}+k_{3}\right)$, both result in oxidation of substrate but involve both diffusion to the active site and electron transfer. Although $k_{2}$ and $k_{3}$ are nominally electron transfer steps that generate the radical intermediate, the observed rate constant appears to be dominated by the diffusional dissociation from the binding site and subsequent attack water. The analysis suggests a dominant role for a bimolecular solution component in the kinetics of substrate oxidation by DHP and has implications for the mechanism of the entire peroxidase family.

Acknowledgment. S.F. and M.K.T. were supported by Army Research Office Grant 52278-LS. H.M. thanks North Carolina State University for financial assistance. We thank Accelrys, Inc. for use of the DMol3 DFT code.

Supporting Information Available: Derivation of eq 1. This material is available free of charge via the Internet at http:// pubs.acs.org.

\section{References and Notes}

(1) Thompson, M. K.; Davis, M. F.; de Sorrano, V.; Howes, B. D. Smulevich, G.; Franzen, S. Biophys. J. 2010, 99, 1586-1595.

(2) LaCount, M. W.; Zhang, E.; Chen, Y. P.; Han, K.; Whitton, M. M.; Lincoln, D. E.; Woodin, S. A.; Lebioda, L. J. Biol. Chem. 2000, 275, 18712

(3) Davis, M. F.; Bobay, B. G.; Franzen, S. Biochemistry 2010, 49, 1199.

(4) de Serrano, V.; Chen, Z.; Davis, M. F.; Franzen, S. Acta Crystallogr., Sect. D: Biol. Crystallogr. 2007, D63, 1094.

(5) Chen, Z.; De Serrano, V.; Betts, L.; Franzen, S. Acta Crystallogr., Sect. D: Biol. Crystallogr. 2009, 65, 34.

(6) Nicoletti, F. P.; Thompson, M. K.; Howes, B. D.; Franzen, S.; Smulevich, G. Biochemistry 2010, 49, 1903.

(7) Han, K.; Woodin, S. A.; Lincoln, D. E.; Fielman, K. T.; Ely, B. Mar. Biotechnol. 2001, 3, 287.

(8) de Serrano, V.; D'Antonio, J.; Franzen, S.; Ghiladi, R. A. Acta Crystallogr., Sect. D: Biol. Crystallogr. 2010, 66, 529.

(9) D'Antonio, J.; D'Antonio, E. L.; Thompson, M. K.; Bowden, E. F.; Smirnova, T.; Franzen, S.; Ghiladi, R. A. Biochemistry 2010, 49, 6600.

(10) Ator, M. A.; Montellano, O. D. J. Biol. Chem. 1987, 262, 1542.

(11) Sharp, K. H.; Moody, P. C. E.; Brown, K. A.; Raven, E. L. Biochemistry 2004, 43, 8644.

(12) Feducia, J.; Dumarieh, R.; Gilvey, L. B. G.; Smirnova, T.; Franzen, S.; Ghiladi, R. A. Biochemistry 2009, 48, 995.
(13) Witting, P. K.; Mauk, A. G.; Lay, P. A. Biochemistry 2002, 41, 11495 .

(14) Hildebrand, D. P.; Lim, K. Y.; Rosell, F. I.; Twitchett, M. B.; Wan, L. G.; Mauk, A. G. J. Inorg. Biochem. 1998, 70, 11.

(15) Wan, L. L.; Twitchett, M. B.; Eltis, L. D.; Mauk, A. G.; Smith, M. Proc. Natl. Acad. Sci. U.S.A. 1998, 95, 12825.

(16) Matsui, T.; Ozaki, S.; Watanabe, Y. J. Am. Chem. Soc. 1999, 121, 9952.

(17) Lardinois, O. M.; de Montellano, P. R. O. J. Biol. Chem. 2001, $276,23186$.

(18) Tsaprailis, G.; English, A. M. J. Biol. Inorg. Chem. 2003, 8, 248.

(19) Wright, P. J.; English, A. M. J. Am. Chem. Soc. 2003, 125, 8655.

(20) Harvey, P. J.; Floris, R.; Lundell, T.; Palmer, J. M.; Schoemaker, H. E.; Wever, R. Biochem. Soc. Trans. 1992, 20, 345.

(21) Yamada, K.; Shibuya, T.; Noda, M.; Uchiyama, N.; Kashiwada,

A.; Matsuda, K.; Hirata, M. Biosci. Biotechnol. Biochem. 2007, 71, 2503.

(22) Dunford, H. B. Xenobiotica 1995, 25, 725.

(23) Lincoln, D. E.; Fielman, K. T.; Marinelli, R. L.; Woodin, S. A. Biochem. Syst. Ecol. 2005, 33, 559.

(24) Davidenko, T. I.; Oseychuk, O. V.; Sevastyanov, O. V.; Romanovskaya, I. I. Appl. Biochem. Microbiol. 2004, 40, 542.

(25) Franzen, S.; Chaudhary, C.; Belyea, J.; Gilvey, L.; Davis, M. F.;

Sit, T. L.; Lommel, S. A. Biochemistry 2006, 45, 9085.

(26) Dunford, B. H. Heme Peroxidases; John Wiley and Sons: New York, 1999.

(27) Belyea, J.; Gilvey, L. B.; Davis, M. F.; Godek, M.; Sit, T. L.; Lommel, S. A.; Franzen, S. Biochemistry 2005, 44, 15637.

(28) Franzen, S.; Gilvey, L. B.; Belyea, J. L. Biochim. Biophys. Acta 2007, 1774, 121.

(29) Perdew, J. P.; Burke, K.; Ernzerhof, M. Phys. Rev. Lett. 1996, 77, 3865

(30) Andzelm, J.; King-Smith, R. D.; Fitzgerald, G. Chem. Phys. Lett. 2001, 335, 321.

(31) Baker, J.; Kessi, A.; Delley, B. J. Chem. Phys. 1996, 105, 192.

(32) Delley, B. J. Chem. Phys. 1990, 92, 508.

(33) Delley, B. J. Chem. Phys. 2000, 113, 7756

(34) Weinert, M.; Davenport, J. W. Phys. Rev. B 1992, 45, 13709.

(35) Andzelm, J.; Kolmel, C.; Klamt, A. J. Chem. Phys. 1995, 103, 9312.

(36) Lente, G.; Espenson, J. H. Int. J. Chem. Kinet. 2004, 36, 449.

(37) Dunford, H. B. J. Biol. Inorg. Chem. 2001, 6, 819.

(38) Davis, M. F.; Gracz, H.; Vendeix, F. A. P.; de Serrano, V.; Somasundaram, A.; Decatur, S. M.; Franzen, S. Biochemistry 2009, 48, 2164

(39) Nienhaus, K.; Nickel, E.; Davis, M. F.; Franzen, S.; Nienhaus, G. U. Biochemistry 2008, 47, 12985.

(40) Smirnova, T. I.; Weber, R. T.; Davis, M. F.; Franzen, S. J. Am. Chem. Soc. 2008, 130, 2128.

(41) Khopde, S. M.; Priyadarsini, K. I. Biophys. Chem. 2000, 88, 103.

(42) Folkes, L. K.; Candeias, L. P. FEBS Lett. 1997, 412, 305.

JP1014516 